\title{
Ensino de ciências e os desafios do século XXI: entre a crítica e a confiança na ciência ${ }^{+}$
}

Alexandre Luis Junges ${ }^{1}$

Universidade Federal do Rio Grande do Sul - Campus Litoral Norte

Tramandaí - RS

Tobias Espinosa ${ }^{l}$

Universidade Federal do Rio Grande - Campus Santo Antônio da Patrulha Santo Antônio da Patrulha - RS

\section{Resumo}

O presente ensaio reflete sobre o papel do ensino de ciências frente aos desafios colocados pelas diferentes questões sociocientificas que permeiam a sociedade contemporânea. Na medida em que a ciência desempenha importante função na busca de soluções para tais questões, como as crises socioambientais e de saúde pública, é também imprescindivel que o ensino de ciências fomente um entendimento que possibilite avaliar informações científicas e distingui-las daquelas que podemos chamar de pseudocientíficas. Contudo, na busca por fomentar essa capacidade avaliativa no aluno, o ensino de ciências corre o risco de incorrer numa valorização excessiva do ideal crítico que visa a autonomia intelectual do aluno, muitas vezes expresso num ceticismo que elege a dúvida pela dúvida. Neste ensaio, problematizamos algumas consequências indesejáveis dessa postura, entre as quais está a perda de confiança na própria ciência. Para tanto, propomos reflexões que: (1) orientam o ensino de ciências para uma confiança na ciência, sem perder a criticidade com relação ao fazer científico; (2) problematizam a justificativa de uma educação científica voltada exclusivamente para a autonomia intelectual do educando que elege a dúvida e o ceticismo como objetivos de ensino. Nessa discussão acentuamos a importância de uma "confiança equilibrada" em relação à ciência, destacando a confiança como elemento complementar ao exercício da dúvida e da

\footnotetext{
${ }^{+}$Science education and the challenges of the 21 st century: between criticism and trust in science

* Recebido: junho de 2020. Aceito: novembro de 2020.

${ }^{1}$ E-mails: alexandre.junges@ufrgs.br; tobiasespinosa@furg.br
} 
crítica. Ao final, apresentamos algumas reflexões e possíveis desdobramentos dessa temática para o contexto da sala de aula e da educação científica.

Palavras-chave: Questões Sociocientíficas; Ceticismo; Autonomia Intelectual; Confiança na Ciência.

\begin{abstract}
This essay reflects on the role of science education in the face of the challenges caused by the different socio-scientific issues that surface from the contemporary society. Inasmuch science plays an important role building solution to issues as socio-environmental and public health crises, it is also essential that science education fosters an understanding that makes it possible to evaluate scientific information and distinguish it from pseudoscience. However, to foster this evaluative capacity in the student, science education runs the risk of incurring an excessive valuation of the critical ideal that aims at the student's intellectual independence, often expressed in a skepticism that elects doubt by doubt. In this essay, we problematize some undesirable consequences of this attitude, including the loss of confidence in science. To this end, we propose reflections that: (1) guide science education towards a confidence in science, without losing criticality regarding scientific practice; (2) problematize the justification for a scientific education focused exclusively on the intellectual independence of the student who chooses doubt and skepticism as teaching aims. In this discussion, we emphasize the importance of a "balanced trust" with science, highlighting trust as a complementary element to the exercise of doubt and criticism. Finally, we present some reflections and possible developments of this topic to the context of the classroom and science education.
\end{abstract}

Keywords: Socio-Scientific Issues; Skepticism; Intellectual Independence; Trust in Science.

\title{
I. Introdução
}

O início do século 21 tem sido marcado por acontecimentos que nos desafiam em escala local e global. Os desastres de Mariana e Brumadinho em 2015 e 2019 no estado de Minas Gerais, o constante desmatamento e queimadas na Amazônia, a perda da 
biodiversidade, os riscos de pesticidas e alimentos geneticamente modificados, os perigos do armamento nuclear, as mudanças climáticas e a recente crise de saúde pública causada pela pandemia do coronavírus constituem realidades desafiadoras da sociedade atual, seja brasileira ou mundial. Como observam os autores de uma reportagem de 1 de abril de 2020 "no início do século 21, não há nada mais previsível do que desastres"2.

É verdade que nem todos os desastres podem ser evitados, mas certamente evitar desastres, como a solução de crises ambientais e de saúde, requer a ação conjunta de diversos campos do conhecimento e principalmente ações na forma de políticas públicas. Dificilmente poder-se-ia negar que a ciência não é um elemento fundamental a ser considerado na orientação dessas políticas, mesmo quando a ciência, ou algum desenvolvimento científico e tecnológico específico, contribuiu para a instalação do problema. Afinal, a mesma ciência que deu origem ao motor a combustão possibilitou a queima acelerada de combustíveis fósseis que libera gases estufa causadores do aquecimento global. Por outro lado, é também a mesma ciência que possibilitou um conhecimento da dinâmica do sistema terrestre capaz de nos alertar e orientar sobre os riscos das mudanças climáticas (IPCC, 2013). É também essa ciência que poderá fornecer uma vacina capaz de controlar ou evitar novos surtos do novo coronavírus.

Ao mesmo tempo, tão importante quanto solucionar uma crise é a capacidade de avaliar os riscos de sua ocorrência. Especialistas de epidemiologia têm alertado a humanidade dos riscos de ocorrência de pandemias e avanços têm sido feitos para mitigar seus impactos, apesar de ainda insuficientes (MADHAV et al., 2017). De fato, como evidenciado pela pandemia do novo coronavírus, governos em diferentes partes do mundo se mostraram mais ou menos surpresos com o anúncio da pandemia pela Organização Mundial de Saúde, muitos inclusive, num primeiro momento, respondendo tardiamente e até mesmo tentando negar a sua realidade, enquanto que o despreparo e a falta de recursos de muitos sistemas de saúde ficavam evidentes ${ }^{3}$.

Dessa forma, diante dos desafios sociais e ambientais colocados pelas diferentes questões sociocientíficas deste século, fica cada vez mais evidente a necessidade de amparar decisões em evidências científicas. Ao mesmo tempo, percebe-se também que a sociedade espera respostas da comunidade científica, de modo que boa parte da agenda científica atual é ditada pelas necessidades da sociedade. Exemplo disso é a corrida científica de laboratórios em busca de uma vacina contra o coronavírus. Assim, mesmo que o papel e a relação da ciência com a sociedade sejam mais complexos do que aqui descrito, o que cabe notar é que a ciência, representada pela comunidade e instituições científicas, é uma conquista da sociedade contemporânea cujo papel é imprescindível no enfrentamento de crises que haverão de vir.

\footnotetext{
${ }^{2}$ A reportagem pode ser acessada em: $<\mathrm{https} / / / \mathrm{rmi}$.org/covid-19-and-climate-risk-mitigation-and-resilience/>.

${ }^{3}$ O Índice Global de Segurança e Saúde - que apresenta resultados de avaliações da capacidade global de segurança em saúde frente ao risco de epidemias e pandemias - pode ser acessado em: $<$ https://www.ghsindex.org/>.
} 
Diante disso, podemos questionar o papel do ensino de ciências na sociedade do século 21. Mais precisamente, qual o papel e a postura esperados para o ensino de ciências com respeito à ciência e à comunidade científica frente ao enfrentamento de questões sociocientíficas? E quais objetivos de ensino seriam desejáveis frente a promoção de um letramento científico do educando nesse contexto? De fato, muitos autores de diferentes orientações teóricas forneceram respostas distintas a essas questões, de modo que dificilmente poderemos dizer algo novo. Dessa forma, nosso objetivo não consiste em introduzir novas respostas, mas problematizar alguns temas presentes nos debates da literatura, buscando organizar ideias e conceitos-chave que consideramos essenciais para a educação científica contemporânea.

No presente ensaio, tomando como ponto de partida debates na área de ensino de ciências sobre o ensino de questões sociocientíficas $(\mathrm{QSCs})^{4}$, abordamos temas como o ceticismo, confiança na ciência e autonomia intelectual do aluno frente a tópicos científicos complexos presentes nessas questões. Em especial, como alunos podem tomar posição diante de temas científicos complexos que se apresentam na esfera pública como dilemas científicos e sociais (e.g., aquecimento global, uso de pesticidas, alimentos geneticamente modificados etc.). Ou seja, o enfoque deste ensaio é sobre como alunos lidam com a dimensão científica das QSCs, interpretando consensos, desacordos, argumentos e declarações com conteúdos científicos apresentadas pela comunidade científica ou por um cientista individual.

Assim, partindo de abordagens teóricas de diferentes autores que se ocuparam com a temática da confiança e autonomia intelectual do aluno frente à ciência envolvida nas QSCs, acentuamos a importância da confiança como elemento indispensável, tanto para o funcionamento da ciência como instituição, como para o ensino de ciências. Ou seja, propomos reflexões que: (1) orientam o ensino de ciências para uma confiança na ciência, sem perder a criticidade com relação ao fazer científico; (2) problematizam a justificativa de uma educação científica voltada exclusivamente para a autonomia intelectual do educando que elege a dúvida e o ceticismo como objetivos de ensino. Dessa forma, defendemos uma educação científica que, dentre outras virtudes, ensina as pessoas a lidar com a ciência, e com os cientistas, apesar de sua falta de conhecimento científico, distanciando-as do ceticismo e do dogmatismo e aproximando-as de uma postura de confiança equilibrada na ciência (NORRIS, 1995, 1997; KOLSTO, 2001; LEVINSON, 2012; FENSHAM, 2014).

\section{Controvérsia sobre o ensino de ciências no contexto de Questões Sociocientíficas}

Recentemente a educação científica tem manifestado grande interesse no ensino de QSCs. Autores têm destacado que a instrução organizada em torno de QSCs tem o potencial de motivar os estudantes, melhorar a aprendizagem de conteúdos, contextualizar o ensino de

\footnotetext{
${ }^{4}$ Questões Sociocientíficas podem ser conceituadas como sendo questões ou dilemas sociais que possuem ligações conceituais e/ou tecnológicas com a ciência (SADLER; MURAKAMI, 2014).
} 
Ciências (inclusive de aspectos da Natureza da Ciência), engajando o aluno com a ciência relacionada às questões que extrapolam os limites corriqueiros da sala de aula, bem como desenvolver habilidades de pensamento de ordem superior (SADLER; MURAKAMI, 2014; HODSON, 2018). O ensino baseado em QSCs é um movimento que compartilha com o campo mais amplo, conhecido como CTSA (Ciência, Tecnologia, Sociedade e Ambiente) (PEDRETTI; NAZIR, 2011), a visão de uma educação científica voltada para o letramento científico (scientific literacy), o exercício da cidadania (science for citizenship) e a promoção da democracia e justiça social.

Contudo, apesar de um interesse comum na inserção de questões sociocientíficas na sala de aula, autores da área de ensino de ciências frequentemente divergem sobre como abordar as QSCs em sala de aula. Surgem assim dificuldades e divergências quanto à seleção do conteúdo relacionado a uma determinada QSC, qual aspecto ensinar como controverso e qual ensinar como consolidado ${ }^{5}$, quais características relacionadas à natureza do conhecimento científico devem ser exploradas e quais objetivos de ensino devem ser perseguidos.

Um exemplo desse tipo de discordância é o debate ocorrido na revista Cultural Studies in Science Education em torno do ensino das questões sociocientíficas das mudanças climáticas. Os autores não apenas manifestam discordâncias sobre o que ensinar como controverso nesse contexto, mas também discordam sobre o objetivo educacional a ser perseguido. No centro dessa discussão sobre os objetivos da educação científica encontra-se o ideal da autonomia intelectual do aluno frente ao conhecimento científico e frente à comunidade de especialistas, no caso, a comunidade científica relacionada à questão sociocientífica das mudanças climáticas. (BRYCE; DAY, 2014; FENSHAM, 2014; SANTOS, 2014; COLUCCI-GRAY, 2014).

Assim, por exemplo, em Bryce e Day (2014) encontramos uma defesa de um ensino de ciências que elege a dúvida e o ceticismo como ideais de ensino. Os autores partem da observação de que o conhecimento científico é eminentemente provisório e contestável, dando destaque ao papel que a dúvida e o ceticismo desempenham no avanço do conhecimento científico. Dentro desse espírito, argumentam que o ensino de ciências deve encorajar o ceticismo e a dúvida no contexto de questões sociocientíficas, buscando ensinar os alunos sobre "como pensar" e não sobre "o que pensar". Assim, argumentam em favor da necessidade de um ensino de ciências em que alunos sejam ensinados, explicitamente, a serem céticos e serem capazes de identificar vieses em alegações científicas e, desse modo, alcançar suas próprias conclusões baseadas no balanço das evidências. Ainda, no contexto da temática das mudanças climáticas, tendo em vista a dimensão controversa que o tema possui na esfera pública, Bryce e Day (2014) consideram que o ensino da temática deve explorar as diferentes perspectivas sobre o tema, enfatizando a dúvida e o ceticismo sobre a temática.

\footnotetext{
${ }^{5}$ No presente ensaio, seguindo Freudenthal (2000), quando empregamos o termo "controvérsias científicas" nos referimos unicamente àquelas controvérsias onde a disputa se dá sobre questões envolvendo conteúdo científico.
} 
Assim, destacam a necessidade de um ensino sobre mudança climática e aquecimento global que engloba outras perspectivas para além daquela considerada consensual, especialmente a perspectiva dos céticos, de modo a evitar vieses e o favorecimento de uma adesão acrítica ao consenso estabelecido pela maioria dos cientistas ${ }^{6}$.

Fensham (2014) fornece uma resposta crítica ao artigo de Bryce e Day (2014). Diferente da posição desses autores, que elegem o ceticismo e a dúvida como objetivos centrais da educação científica, o autor argumenta que, embora o cultivo do ceticismo seja importante em muitos contextos, a confiança na ciência é um ingrediente igualmente importante na educação científica. Nesse sentido, os alunos também devem aprender quando e por que é adequado confiar na ciência.

Para Fensham (2014), a ênfase dada por Bryce e Day ao ceticismo e à dúvida, em que alunos são encorajados a inferir "conclusões próprias" a partir do balanço das evidências, indicaria que os autores estariam adotando uma perspectiva de letramento científico que elege a autonomia intelectual do aluno como objetivo. Ou seja, a ideia de que o aluno desenvolva a independência de, por conta própria, acessar as razões e evidências que dão suporte à determinada teoria ou alegação científica e, assim, adquirir autonomia intelectual. Segundo Fensham, essa perspectiva seria consistente com a imagem do aluno como "mini cientista". Em sua crítica aos autores, Fensham destaca a diferença entre a cultura escolar e a cultura científica. Assim, argumenta que por mais que estudantes e professores possam se esforçar em depurar a evidência, estes não estão na mesma posição epistêmica de cientistas treinados, bem como, não dispõem dos equipamentos para reproduzir os resultados investigados. Em outras palavras, estudantes não estariam em posição de julgar a verdade de asserções científicas de modo independente, mas estariam numa condição de dependência epistêmica para com cientistas.

Fensham (2014) considera, assim, que é preciso conciliar a atitude de ceticismo com uma postura de confiança na ciência, buscando ensinar os alunos a serem capazes de diferenciar quando o ceticismo ou a confiança são apropriados. Por exemplo, aprendendo a diferenciar entre a "ciência estabelecida" e a "ciência emergente", bem como diferenciar entre uma alegação científica feita pela comunidade científica e uma alegação feita por um cientista individual independente do seu status aparente. Como argumentamos em seguida, existe uma diferença importante entre promover uma confiança equilibrada na comunidade científica e promover uma confiança no cientista individual, uma vez que nem sempre o cientista poderá expressar, na esfera pública, as visões compartilhadas pela comunidade de especialistas a qual ele pertence.

Assim, diferente da perspectiva do aluno mini cientista, Fensham defende a imagem do aluno como "cidadão informado cientificamente" (science informed citizen). Nessa

\footnotetext{
${ }^{6}$ Perspectivas similares que enfatizam o papel do ceticismo e da consciência reflexiva na abordagem do tema, no intuito de fornecer uma descrição balanceada da questão, apresentando ambos os lados do debate sobre as causas do aquecimento global, são discutidas por Santos (2014) e Colucci-Gray (2014).
} 
perspectiva, o ceticismo também pode fazer parte do ensino de questões sociocientíficas, mas não é condição suficiente para tal ensino, pois deveria ser complementado com o elemento da confiança na ciência. Para Fensham, futuros cidadãos devem ser capazes de tomar decisões informadas sobre QSCs e desse modo devem desenvolver o conhecimento para decidir sobre quando confiar na ciência (FENSHAM, 2014).

Ao mesmo tempo, pode-se destacar outras diferenças entre os autores no que tange ao ensino da questão sociocientífica das mudanças climáticas. Enquanto que Bryce e Day (2014) sugerem adotar uma postura em que o tema é ensinado como constituindo uma controvérsia científica, dando igual peso a ambos os lados do debate, ou seja, entre a visão consensual e os céticos, Fensham (2014) parece adotar uma postura distinta. Embora o autor não deixe claro sua posição sobre como o tema deveria ser ensinado, se constituindo uma controvérsia científica ou não, fica evidente que sua posição é distinta dos autores quando questiona por que, num extenso artigo dedicado à questão da dúvida e ao ceticismo, Bryce e Day (2014) não tenham feito menção ao fato amplamente documentado de que existe uma campanha de promoção da dúvida e da desinformação sobre aquecimento global promovida pela indústria de combustíveis fósseis ${ }^{7}$.

Esse breve exemplo demonstra a dificuldade e o desafio da educação científica numa perspectiva CTSA para o século 21, uma vez que muitos dos temas relevantes da sociedade atual são temas sociocientíficos complexos. Como exemplificado, autores do campo da educação científica apresentam consideráveis diferenças de interpretação sobre como abordar temas complexos e quais objetivos da educação científica devem ser priorizados visando o letramento científico. Nesse sentido, a partir das questões surgidas nesse debate, aprofundaremos a reflexão em torno da questão da confiança e do papel da autonomia intelectual do aluno no contexto de temas sociocientíficos.

\section{O ideal da autonomia intelectual e a confiança na ciência}

O termo "letramento científico"" tem sido usado no ensino de ciências desde meados do século 20, abarcando uma variedade de significados (DEBOER, 2000; SASSERON; CARVALHO, 2011; CUNHA, 2017, 2018a, 2018b). Segundo DeBoer (2005), já entre os

\footnotetext{
${ }^{7}$ Aqui cabe destacar, por exemplo, os riscos e consequências indesejadas de ensinar como controverso o que não é controverso ou ensinar como resolvido o que é controverso, o que poderia, segundo autores como Hand (2008), comprometer o objetivo educacional. Surgem, assim, questões importantes sobre a natureza das controvérsias científicas (MCMULLIN, 1987) e como diferenciá-las de outros tipos de disputas. Dessa forma, a questão sobre "quando devemos ensinar algo como sendo controverso?" (HAND, 2008), passa a ser uma questão igualmente desafiadora (JUNGES; MASSONI, 2018)

${ }^{8}$ O termo "scientific literacy", além de polissêmico, ganhou uma diversidade semântica na literatura. Em língua portuguesa, por exemplo, encontramos os termos "letramento científico e "alfabetização científica". Apesar de serem usualmente utilizados como sinônimos, Cunha (2018b) argumenta que os autores nacionais da área de Educação em Ciências que optam pelo termo "letramento científico" priorizam o escrutínio das funções sociais das ciências e das tecnologias, bem como o desenvolvimento de valores e atitudes em relação a elas.
} 
primeiros defensores da inserção de uma educação científica para a população em geral, como John Dewey no início do século 20, a justificativa envolvia a ideia de que a educação científica poderia promover a autonomia intelectual do aluno ampliando sua capacidade de tomada de decisão e participação social. Em uma revisão da literatura acerca dos significados do letramento científico, Kemp (2000) destaca que a autonomia intelectual está entre os elementos que são mais frequentemente associados ao termo. Da mesma forma, dentro da tradição de ensino associada ao movimento CTSA (Ciência Tecnologia Sociedade e Ambiente) é preconizada uma educação científica voltada para o letramento científico dando destaque à capacidade argumentativa do aluno, à atitude crítica e à tomada de decisão, sendo este letramento científico frequentemente associado ao ideal da autonomia intelectual, de modo que o aluno seja capaz de, por conta própria, acessar as razões e evidências que dão suporte à determinada teoria ou alegação científica ${ }^{9}$.

Contudo, como visto, se por um lado uma busca de autonomia intelectual é desejável, cabe ponderar sobre o papel da dúvida e do ceticismo como objetivos educacionais, na medida em que poderiam incutir no aluno uma atitude crítica que o levaria a duvidar ou mesmo tornar-se cético com respeito aos especialistas e à própria ciência de determinada área. De fato, mesmo autores como Bruno Latour, por vezes crítico da ciência, têm alertado para os riscos de um ceticismo desmedido em relação à ciência, em especial, envolvendo a desconfiança excessiva de boas questões de fato e da retórica de extremistas perigosos que "[...] estão usando o mesmo argumento da construção social para destruir evidências duramente conquistadas que poderiam salvar nossas vidas" (LATOUR, 2004, p. 227, tradução nossa).

No contexto da temática do aquecimento global, Levinson (2012) chama a atenção para o cuidado de não fomentar uma atitude demasiadamente cética entre os alunos com respeito ao conhecimento científico. Ele escreve:

\begin{abstract}
Ao ensinar e discutir aquecimento global deve-se evitar a via de priorizar o desenvolvimento de "know-how" suficiente para questionar especialistas, embora uma compreensão básica do processo seja importante. Ao invés disso é preciso concentrar-se em desenvolver a compreensão dos processos sociais através dos quais os fatos são tornados públicos, e como a confiança e o ceticismo dessas relações apoiam o papel da ciência como conhecimento condicional, mas evitando o relativismo que dá credibilidade aos céticos do clima (LEVINSON, 2012, p. 695, tradução nossa).
\end{abstract}

Além disso, como argumentaremos, a execução do ideal da autonomia intelectual depara-se, também, com limites práticos quando nos voltamos para campos científicos complexos, onde a avaliação das evidências relevantes requer um treinamento especializado. Dessa maneira, lidar com temas complexos do mundo real, como são as questões

\footnotetext{
${ }^{9}$ Encontramos essa postura crítica com respeito à ciência e aos especialistas nas abordagens CTS com autores como Auler e Delizoicov (2001) e Santos (2007).
} 
sociocientíficas, parece exigir uma "visão ampliada" do letramento científico, indo além da busca da autonomia intelectual, especialmente, quando esta é associada exclusivamente com a dúvida e o ceticismo como objetivos da educação científica.

De fato, Kolsto (2001) em sua longa discussão epistemológica sobre o ensino de Questões Sociocientíficas também percebe essa ameaça de um ceticismo desproporcional frente à ciência. Na medida em que Kolsto (2001) se ocupa do que ele chama de "questões sociocientíficas controversas", o autor aponta para as dificuldades do leigo em interpretar os desacordos percebidos entre os especialistas, bem como a tendência do leigo em interpretar desacordos entre cientistas como sendo devido a preconceitos e vieses individuais dos cientistas, o que poderia implicar em uma perda de confiança na ciência.

De fato, parte da motivação da discussão teórica de Fensham (2014), e mesmo Kolsto (2001), encontra-se na discussão sobre o papel da confiança e da autonomia intelectual feita por Norris (1995). O autor aborda essas questões sob uma perspectiva epistemológica, discutindo o caráter comunitário do fazer científico. Como consequências do caráter comunitário da ciência, o autor destaca a dependência epistêmica e a confiança entre pares especialistas e entre o leigo e o especialista, discussão esta que Norris remete a Hardwig $(1985,1991)$.

Este último discute de modo detalhado alguns dos temas diretamente relacionados ao que tem sido conhecido por epistemologia do testemunho ${ }^{10}$ (HARDWIG, 1985, 1991). De fato, como é reconhecido pela epistemologia do testemunho, em diversos contextos compartilhamos e mantemos crenças sobre coisas para as quais não somos capazes de elencar as evidências que as sustentam. Assim, por exemplo, acreditamos que cigarro causa câncer, que café em excesso causa insônia, que o monte Everest é o mais alto do planeta, que a Lua possui uma face oculta, que quarks são partículas fundamentais, que o Universo teve início há 13,7 bilhões de anos etc. Apesar de ser possível adquirir evidência para muitas dessas proposições, não somos capazes de averiguar a evidência direta que sustenta todas elas. Como escreve Hardwig (1985, p. 335, tradução nossa): "Eu acredito demais; há muitas evidências relevantes (muitas delas disponíveis somente após extenso treinamento especializado); o intelecto é muito pequeno e a vida é muito curta". Dessa forma, como leigos em diversos assuntos, boa parte da justificação de muitas de nossas crenças reside na autoridade do testemunho de especialistas que se ocuparam com a evidência relevante que as justifica.

De modo similar, essa dependência epistêmica relacionada ao testemunho do especialista frente ao leigo também está presente no testemunho de especialista para especialista. Isso pode ser constatado se observarmos que a comunidade científica é formada por nichos de especialidades, onde nenhum dos membros da comunidade científica é particularmente capaz de dominar todos os aspectos e facetas de um dado problema

\footnotetext{
${ }^{10}$ Sobre o papel do testemunho na formação e justificação de nossas crenças, bem como se o testemunho pode ser considerado uma fonte básica de conhecimento, pode-se consultar o verbete "Epistemological Problems of Testimony" $<$ https://plato.stanford.edu/entries/testimony-episprob/>.
} 
investigado. Muitos artigos científicos da atualidade são escritos por grupos (times interdisciplinares) envolvendo dezenas de cientistas. Hardwig (1985) destaca um artigo sobre física de partículas, publicado na revista Physical Review Letters, escrito por 99 autores em que os próprios autores reconheciam que nenhum deles teria o conhecimento e habilidade para realizar o experimento individualmente. Como destaca Norris (1995, p. 207, tradução nossa), "nenhum cientista pode ter razões para todas as proposições da ciência que ele aceita, nenhum cientista pode depender apenas dos resultados da sua investigação individual".

Dessa forma, a confiança no testemunho e trabalho dos colegas (pares) cientistas é um ingrediente essencial e necessário ao desenvolvimento científico ${ }^{11}$. É o testemunho de um especialista para o outro que conecta as evidências coletadas por diferentes pesquisadores em um todo unificado que pode justificar uma teoria (HARDWIG, 1991) ${ }^{12}$.

Esse elemento cooperativo entre especialistas acentua o aspecto comunitário da ciência. Assim, a ciência, como prática conduzida por uma comunidade de cientistas, é governada por uma ordem moral de respeito a uma elite de especialistas formada por membros que possuem conhecimento e habilidades para a prática da ciência (NORRIS, 1995) ${ }^{13}$. A ênfase na ciência como atividade desenvolvida por comunidades de especialistas treinados também pode ser encontrada em Thomas Kuhn. Na obra "A Estrutura das Revoluções Científicas", Kuhn já destacava o papel do treino e da iniciação científica necessários para a interpretação de dados e resultados científicos. Escreve Kuhn (1970):

Uma das leis mais fortes, ainda que não escrita, da vida cientifica é a proibição de apelar a chefes de Estado ou ao povo em geral quando está em jogo um assunto relativo à ciência. O reconhecimento da existência de um grupo profissional competente e sua aceitação como árbitro exclusivo das realizações profissionais possui outras implicações. Os membros do grupo, enquanto indivíduos e em virtude

\footnotetext{
${ }^{11}$ De modo similar, John Ziman (1996, 2000) argumenta que a confiança no conhecimento científico advém do caráter social da instituição científica. Nessa instituição, os membros compartilham valores, dos quais os princípios de consensibilidade (que se baseia na capacidade humana natural de reconhecer padrões e na exigência de que os fenômenos estudados sejam passíveis de se tornarem consenso) e consensualidade têm papel de destaque.

${ }^{12}$ Ao defender que o conhecimento científico frequentemente é baseado na relação entre os seus membros e, portanto, na confiança, Hardwig vai além, defendendo a implicação de que o conhecimento científico repousa em última instância na fidedignidade, ou "trustworthiness" (caráter, competência, honestidade), dos seus membros. Adler (1994) concorda que o testemunho requer confiança, contudo discorda da alegação de Hardwig de que o conhecimento científico em última instância repousa na confiança. Para Adler, retomando um argumento de David Hume, embora o testemunho seja uma fonte importante de conhecimento, a manutenção da justificação das crenças testemunhais requer o apoio de outras fontes (como raciocínio) e informações de fundo compartilhadas pelos cientistas.

${ }^{13}$ Tal ordem moral estaria baseada em um princípio do tipo "diga apenas o que você honestamente acredita ser verdade" (NORRIS, 1995, p. 204), onde aquilo que se pode crer de forma honesta é o que foi justificado usando os métodos e padrões sancionados pela comunidade científica. Procedimentos adicionais, como o processo de revisão por pares (peer review), têm a função de checar se os métodos e padrões da comunidade foram seguidos. É claro que tais procedimentos e métodos não são infalíveis e falsidades podem, inclusive, não serem detectadas por vários anos.
} 
de seu treino e experiências comuns, devem ser vistos como os únicos conhecedores das regras do jogo ou de algum critério equivalente para julgamentos inequivocos (KUHN, 1970, p. 212).

Dessa forma, seguindo Hardwig e Norris pode-se notar que no campo científico a autoridade epistêmica não reside tanto no indivíduo, mas em comunidades de especialistas. Essa afirmação poderia causar a suspeita de que tal posição incorre numa adesão dogmática às ortodoxias científicas representadas pelas comunidades de especialistas. Para evitar esse entendimento, parece-nos importante diferenciar entre o dogmatismo e o que filósofos têm chamado de "conservadorismo epistêmico", segundo o qual "um sujeito está justificado em continuar a aceitar plenamente algo na ausência de uma razão especial contrária" (HARMAN, 1986, p.46, tradução nossa) ${ }^{14}$.

Estendendo esse princípio para o campo científico temos que, quando uma comunidade de especialistas, após anos (às vezes décadas) de debate e controvérsia, finalmente chega a um consenso científico envolvendo a aceitação de determinada teoria, tal consenso não é solapado ou colocado em questão por qualquer alegação feita por um cientista individual. São necessárias "razões especiais" (evidências robustas) para reabrir a discussão sobre a legitimidade da teoria. Ou seja, o ônus da prova para reabrir um debate recai sobre os dissidentes. Tal postura conservadora da comunidade científica não deve ser confundida com dogmatismo, especialmente quando a comunidade científica constantemente avalia e reavalia evidências e responde às objeções feitas.

Voltando ao nosso tema, Norris (1995) observa que a afiliação à ciência vem em vários graus. Alguns indivíduos passam a se tornar especialistas através de estudos de doutorado, pós-doutorado e carreiras como pesquisadores. Há aqueles que estudam a ciência num nível intermediário de profundidade e outros que adquirem apenas uma breve introdução à ciência. Assim, embora o grau de afiliação à ciência ocorra num contínuo, pode-se distinguir entre três níveis de afiliação: o cientista especialista, o professor de ciências da escola e o leigo que frequentou apenas a escola até o nível médio. Em cada nível de afiliação há uma dependência epistêmica com aquele que possui um nível maior de afiliação (Ibid.). Dessa forma, no contexto educacional professores e estudantes estariam numa condição de dependência epistêmica em relação aos cientistas em suas áreas de domínio.

Assim, no que tange a temática do ensino de QSCs, em se tratando de campos científicos complexos, é importante reconhecer que em muitos aspectos há uma forte dependência epistêmica entre especialistas e professores e alunos. Na medida em que o conhecimento científico envolvido em QSCs é, em geral, um conhecimento científico de fronteira, é um objetivo infactível esperar que os alunos alcancem um domínio completo dos

\footnotetext{
${ }^{14}$ Cabe observar que esse é um princípio epistêmico sem relação com o assim chamado "conservadorismo político".
} 
conceitos científicos envolvidos ou que alcancem uma autonomia intelectual frente a tais tópicos complexos (LEVINSON, 2008; KOLSTO, 2001) ${ }^{15}$.

Contudo, isso não significa adotar um modelo tecnocrático em que estudantes devam aderir cegamente à opinião do especialista. Como discutido por Hardwig (1985), existem situações em que o leigo pode racionalmente recusar-se a aceitar a opinião do especialista. Por exemplo, quando há suspeita de que o especialista está atuando de forma tendenciosa, vaidosa, mentindo ou se recusando a reconhecer um erro. A esse respeito Norris (1995) observa que estudantes devem ser orientados sobre o sentido em que o conhecimento repousa na autoridade, mas alertando que tal autoridade é falível. Embora o acesso ao conhecimento científico ocorra, para a maioria de nós, através do testemunho de especialistas, é importante que o aluno saiba questionar e buscar outras opiniões científicas sobre determinada questão.

Norris (1997) observa que, mesmo diante de uma forte dependência epistêmica entre leigo e especialista, é necessário que o ensino de ciência vá além da mera memorização de fatos. O autor emprega o termo "distanciamento epistêmico" para captar parte das motivações que subjazem a ideia de autonomia intelectual. Assim, argumenta que o não-cientista deve desenvolver um distanciamento em relação à ciência, isto é, uma distância cognitiva entre ouvir uma afirmação científica e acreditar que a afirmação é verdadeira. Nesse sentido, uma distância epistêmica nula implica acreditar em tudo que se ouve; e uma distância infinita sugere duvidar de tudo que é dito por cientistas. A posição ideal, segundo o autor, é entre esses extremos. Assim, "ter distância epistêmica da ciência implica que algumas afirmações são ouvidas, mas não aceitas como confiáveis, e que outras são ouvidas e aceitas." (Ibid., p. 253 , tradução nossa). O indivíduo que não possui distanciamento epistêmico sequer questiona a veracidade de uma alegação. Assim, qualquer postura radical diante da ciência, seja ela dogmática, cética, cínica ou relativista, pode ser prejudicial para a educação científica. Como aponta Norris (1984):

[...] atitudes científicas apropriadas consistem em reter o julgamento quando não há razão suficiente para julgar, duvidar quando há razão para duvidar, acreditar cautelosamente quando há razão para acreditar cautelosamente, acreditar fortemente quando há razão para acreditar fortemente e acreditar sem dúvida quando há razões para acreditar sem dúvida (NORRIS, 1984, p. 494, tradução nossa).

Porém, ao defender o ensino por meio de uma atitude crítica e do exercício de um ceticismo sábio, Norris (1995) sugere que o objeto desse ceticismo deva ser a crença no especialista e não propriamente na evidência que dá suporte à alegação científica por ele

\footnotetext{
15 Ademais, dada a característica institucional da ciência, existem posições que não podem ser ocupadas por qualquer indivíduo sem preparação prévia e legitimidade outorgada pelos demais membros da comunidade. Nesse sentido, o ideal da autonomia intelectual transmite a ideia ingênua de que qualquer pessoa, a qualquer momento, pode, por decisão individual, integrar à comunidade científica.
} 
defendida. Ou seja, não seria função do não especialista avaliar a evidência científica (sobre se determinado corpo de evidências justifica uma proposição científica), uma vez que o leigo, no domínio das especialidades científicas, não dispõe do conhecimento, do treino, dos equipamentos e da competência para a realização completa dessa avaliação. Contudo, como acentuado anteriormente, para evitar uma interpretação que sugira uma adesão acrítica a qualquer argumento ou evidência apresentada por um especialista, cabe observar que não se trata de desconsiderar os argumentos e evidências apresentados, mas sim, de reconhecer que em muitos contextos científicos complexos, o leigo precisa reconhecer os limites da sua capacidade de avaliar as evidências e, dessa forma, deverá dispor de outros meios para tomar posição frente ao testemunho de um cientista individual. Para estender esse ponto, cabem aqui algumas reflexões adicionais.

Retomando o conceito de autonomia intelectual, a partir do que foi apresentado, podemos elencar ao menos duas formulações distintas sobre a autonomia intelectual ${ }^{16}:$ (1) estudantes são intelectualmente independentes quando são capazes de julgar por conta própria as evidências que apoiam uma proposição científica; (2) estudantes são intelectualmente independentes quando são capazes de julgar proposições científicas oriundas de fontes testemunhais (alegações feitas por cientistas, passagens de livros, artigos, jornais etc.).

Com base na discussão feita anteriormente, parece-nos improvável que uma autonomia intelectual nos moldes da primeira formulação seja plenamente alcançável no contexto educacional. Contudo, um sentido fraco de autonomia intelectual, nos termos da segunda formulação, parece plausível, uma vez que não exige uma avaliação da evidência que dá suporte à proposição científica (embora possa dispor dessa avaliação evidencial quando possível de ser realizada), mas uma avaliação sobre a confiabilidade da fonte de testemunho ${ }^{17}$.

Dessa forma, pode-se observar que, mesmo diante da dependência epistêmica entre o leigo e o especialista, há espaço para autonomia intelectual quando esta é entendida no sentido fraco (segunda formulação). Essa observação nos parece razoável e permite captar a ideia de que tanto o ensino do conteúdo científico (conceitos, princípios, estrutura matemática etc.) quanto o ensino de aspectos da natureza da ciência (história e filosofia da ciência) são relevantes para o letramento científico. Ou seja, possuir uma compreensão de conceitos científicos, mesmo que num nível intermediário, pode desempenhar um papel importante na

\footnotetext{
${ }^{16}$ Norris (1997, p. 247) discute formulações similares, mas como visto, prefere adotar a ideia de "distanciamento epistêmico".

${ }^{17}$ Contudo, para Hardwig (1991), mesmo essa autonomia no sentido fraco não seria completamente alcançável, uma vez que no processo de avaliação da confiabilidade do testemunho do especialista, o leigo dependerá da consulta a um outro especialista sobre a confiabilidade do primeiro. Hardwig (Ibid., p. 701) discute duas estratégias que podem ser perseguidas: consultar um outro especialista sobre a confiabilidade do primeiro, ou então, consultar a opinião de outro especialista sobre se a evidência fornece justificação para a proposição em discussão. Por sua vez, Adler (1994) apresenta argumentos que dão sustentação à versão fraca de autonomia intelectual. Em que medida o letramento científico pode fomentar uma autonomia que permita uma avaliação da confiabilidade do testemunho de um especialista de modo independente de outros especialistas nos parece um debate em aberto.
} 
avaliação do testemunho de um especialista. Assim, por exemplo, se um especialista dirige-se à esfera pública fazendo uma alegação pseudocientífica que está em flagrante contradição com a ciência amplamente estabelecida (por exemplo, de que o efeito estufa da Terra não existe) o leigo iniciado na ciência, que compreende os aspectos básicos do fenômeno em questão, terá "conhecimentos de fundo" à sua disposição para formar uma opinião sobre o testemunho do especialista. A suspeita, em face do seu distanciamento epistêmico, de que algo possa estar errado com o testemunho do aparente especialista pode, então, levar o leigo a buscar uma segunda opinião ou mesmo, o que seria desejável, averiguar qual é a posição da comunidade científica mais ampla sobre o tema ${ }^{18}$.

Para Norris (1995), o teste mais confiável que os estudantes têm à mão para averiguar a adequação epistêmica de suas crenças científicas é verificar se a comunidade endossa essas crenças. Assim, embora em muitos contextos científicos complexos, o leigo não disponha de independência epistêmica com respeito a julgamentos sobre se determinado corpo de evidências apoia uma hipótese, ele pode adquirir alguma independência epistêmica no que diz respeito à avaliação sobre quais são os especialistas confiáveis de determinada área. Como descreve Norris (1995), a tarefa do não especialista "é determinar quem são os membros mais respeitados da comunidade científica, usando os julgamentos dos membros da própria comunidade científica".

Neste contexto, conhecimentos sobre a natureza da ciência são igualmente relevantes, pois permitem ao aluno colocar questões como: em quais especialistas posso confiar? Estariam os cientistas expressando interesses e opiniões pessoais? Qual a comunidade científica da área? Qual o papel do consenso científico? Posso confiar na ciência? Como observado por Kolsto (2001), uma educação científica cujo objetivo é promover a cidadania deve não apenas prestar atenção ao "conhecimento do conteúdo científico" (knowledge in science), mas também ao "conhecimento que transcende o conteúdo científico" (knowledge about science), sendo esse último uma extensão ampliada do rótulo "Natureza da Ciência".

Podemos, assim, concordar com Fensham (2014) quando defende que o objetivo educacional da ciência escolar é promover uma atitude reflexiva no aluno de modo que este possa saber diferenciar entre alegações de conhecimento científico que devem ser postas em dúvida e aquelas em que se pode confiar. De fato, o caminho para uma educação científica que alcance esse objetivo harmonioso entre a dúvida e a confiança não é tarefa fácil, constituindo um dos aspectos mais desafiadores no ensino de questões sociocientíficas complexas.

\footnotetext{
${ }^{18}$ A diferenciação entre a esfera científica e a esfera social (pública) é importante no trato de questões sociocientíficas, especialmente na análise de controvérsias científicas e na diferenciação entre controvérsias científicas legítimas e controvérsias fabricadas na esfera pública (CECCARELLI, 2011).
} 


\section{Considerações finais}

Neste ensaio, argumentamos que um ensino de ciências que se distancie do ceticismo e do dogmatismo, e sustente uma postura de confiança equilibrada na ciência é importante, sobretudo frente aos desafios sociais contemporâneos colocados pelas questões sociocientíficas. Essa posição vai de encontro àquela que sustenta o ceticismo como fator preponderante da abordagem científica e que defende a autonomia intelectual - no sentido de ter capacidade individual de avaliar os argumentos que sustentam alegações científicas complexas - como objetivo do ensino de ciências. Nesse sentido, concordamos com a declaração de Christopher Norris de que "um dos principais objetivos do ensino de ciências na escola é fornecer às pessoas o meio para lidar, de forma inteligente, com a Ciência e os cientistas, apesar da sua falta de conhecimento científico" (NORRIS, 1995, p. 202, tradução nossa).

Como visto, tal postura frente à educação em ciências, em especial, no contexto de questões sociocientíficas, implica que o ensino de ciências deve fomentar o cultivo de uma postura de equilíbrio entre a dúvida e a confiança na ciência. Assim, embora o aluno possa, a partir do domínio de conteúdos científicos, ser capaz de identificar argumentos científicos falaciosos em determinados casos, este também deve ser ensinado a compreender os limites dessa avaliação, uma vez que em muitas situações, envolvendo questões sociocientíficas, lidamos com conhecimento científico especializado cujo domínio requer treinamentos específicos que não são possíveis de atingir no contexto escolar. Dessa forma, fomentar uma autonomia intelectual no sentido fraco discutido acima, nos parece uma posição plausível, uma vez que essa formulação reconhece a importância do ensino de conteúdos científicos e de habilidades críticas, mas estende seu domínio para a dimensão da natureza da ciência, incluindo aspectos epistêmicos e sociais que refletem sobre o caráter comunitário da atividade científica.

Vemos, assim, que o ensino de questões sociocientíficas impõe consideráveis desafios para educação científica. De fato, preocupados com a importância das dimensões epistêmicas e sociais no ensino de QSCs, autores como Hodson (2018) têm sugerido que no contexto educacional alunos possam ser orientados a analisarem relatos científicos respondendo questões que abordem e fomentem reflexões sobre essas dimensões da natureza da ciência. Por exemplo, questões do tipo:

Quem conduziu a pesquisa e onde ela foi realizada? Como a pesquisa foi financiada? Foi a pesquisa patrocinada e, em caso afirmativo, por quem? [...] Que suposições são feitas e que teorias são utilizadas na argumentação a partir da evidência para a conclusão? Será que os autores usam teorias bem estabelecidas ou, ao invés eles desafiam tais teorias? São possiveis interpretações e conclusões alternativas? Que evidência adicional ajudaria a esclarecer ou resolver as questões? Houve outros estudos realizados por estes cientistas, ou por outros? (HODSON, 2018, p. 30-31) 
Questões como essas, embora não sejam resultado da apresentação teórica feita anteriormente, nos permitem vislumbrar algumas possibilidades iniciais para o ensino de ciências. Por meio delas, discussões sobre as dimensões sociais envolvidas na produção do conhecimento científico podem permitir reflexões em sala de aula sobre o tema da confiança na comunidade científica e no especialista, as quais são particularmente necessárias frente às crescentes ameaças à racionalidade advindas de posturas anticientíficas e negacionistas da ciência.

Como está bem documentado, não raro nos deparamos em diversos contextos da esfera pública, especialmente nas mídias formal (jornais especializados) e informal (redes sociais), com alegações de especialistas ou pseudoespecialistas que flagrantemente destoam da posição da ampla maioria da comunidade de especialistas de uma determinada área. Esse é o caso, por exemplo, dos autodeclarados céticos (ou negacionistas) das mudanças climáticas que negam as causas antropogênicas das mudanças climáticas, em contraste com a posição estabelecida da comunidade científica representada pela Organização Meteorológica Mundial $^{19}$ e o Painel Intergovernamental sobre Mudanças Climáticas (IPCC, 2013). De modo similar, esse também é o caso de alguns médicos que durante a pandemia do coronavírus têm externado declarações que negam os perigos do coronavírus ou que promovem remédios ainda não completamente testados, posições estas que destoam completamente da comunidade de especialistas e da Organização Mundial de Saúde ${ }^{20}$.

Dessa forma, é imprescindível que a educação científica forneça aos alunos os meios para avaliar corretamente tais situações, de modo que possam diferenciar entre afirmações científicas baseadas em evidências e afirmações pseudocientíficas, bem como diferenciar controvérsias científicas legítimas de controvérsias científicas fabricadas (CECCARELLI, 2011). A confiança equilibrada na ciência como instituição composta por uma comunidade de especialistas torna-se imprescindível para reconhecer as assimetrias dos casos acima apresentados, ou seja, de que o ônus da prova recai sobre os dissidentes individuais que desafiam o consenso da comunidade científica ${ }^{21}$, sendo a posição desta última, o melhor que a ciência tem a oferecer até um dado momento, mesmo que este consenso seja sempre falível e passível de revisão.

Como vimos, leigos podem responder questões sobre a confiabilidade de um determinado especialista, questionando, por exemplo, se outros pesquisadores costumam

\footnotetext{
${ }^{19}$ Veja "Statement state of global climate" (WMO): <https://public.wmo.int/en/our-mandate/climate/wmostatement-state-of-global-climate>.

${ }^{20}$ Veja "Perguntas e Respostas - Covid-19":

$<$ https://www.paho.org/bra/index.php?option=com_content\&view=article\&id=6101:covid19\&Itemid=875>.

${ }^{21}$ Existe ampla evidência histórica de que esse é o caso das mudanças climáticas, onde a postura conservadora da comunidade científica frente aos dissidentes céticos tem sido, muitas vezes, erroneamente tachada de "dogmatismo da ortodoxia" (JUNGES; MASSONI, 2018; WEART, 2008). Veja, também, o hipertexto de Spencer Weart em <https://history.aip.org/climate/index.htm>.
} 
concordar com suas alegações (se os argumentos que ele emprega não contradizem teorias amplamente aceitas ou se são argumentos reconhecidos como legítimos pela comunidade científica mais ampla) e se o especialista é considerado como sendo confiável e competente dentro da comunidade acadêmica. Nesse contexto, a estratégia educacional pode envolver uma investigação sobre o desenvolvimento do campo científico em questão, analisando, por exemplo, as publicações dos cientistas que o compõem. É evidente que, para isso, o professor precisa investir tempo no desenvolvimento das habilidades dos estudantes em análise crítica de textos científicos de revistas especializadas (incluindo a análise da qualidade dos periódicos) e de materiais de popularização e divulgação científica expostos em jornais, revistas, televisão e websites (HODSON, 2018).

Por fim, é importante ressaltar que um ensino de ciências que fomente no estudante uma postura de confiança equilibrada na ciência não implica na formação de cidadãos passivos ou acríticos. Implica, por outro lado, na formação cidadã para uma vida social imersa em ciência e tecnologia. A partir de uma educação científica baseada na confiança equilibrada, pode-se incentivar os estudantes (e escolas) a se envolverem em ações sociopolíticas fundamentadas, isto é, medidas que visem impedir ou alcançar mudanças sociais (DESJARDINS et al., 2015). A partir de resultados científicos confiáveis, os alunos podem promover ações diretas (e.g., reciclagem, limpeza de áreas poluídas, economia de energia elétrica, organização de petições e boicotes) e indiretas (e.g., distribuição de panfletos informativos, divulgação de informações em redes sociais) (HODSON, 2014). O ativismo, nessa perspectiva, tem por objetivo modificar a sociedade em termos socialmente mais justos. Nesse sentido, mesmo que o indivíduo não seja capaz de compreender todo um campo de conhecimento para tomar decisões sobre questões sociais que envolvam ciência (como proposto pelo ideal da autonomia intelectual), é razoável pensar que ele é capaz de, a partir de uma confiança equilibrada na ciência, desenvolver ações que levem ao bem-estar social.

\section{Referências bibliográficas}

ADLER, J. Testimony, trust, knowing. The Journal of Philosophy, v. 91, n. 5, p. 264-275, 1994.

AULER, D.; DELIZOICOV, D. Alfabetização científico-tecnológica para quê? ENSAIO Pesquisa em Educação em Ciências, v. 3, n. 1, p. 1-17, 2001.

BRYCE, T. G. K.; DAY, S. P. Scepticism and doubt in science and science education: the complexity of global warming as a socio-scientific issue. Cultural Studies of Science Education, v. 9, p. 599-632, 2014. 
COLUCCI-GRAY, L. Beyond evidence: a critical appraisal of global warming as a socioscientific issue and a reflection on the changing nature of scientific literacy in school. Cultural Studies of Science Education, v. 9, n. 3, p. 633-647, 2014.

CUNHA, R. B. Alfabetização científica ou letramento científico? Interesses envolvidos nas interpretações da noção de scientific literacy. Revista Brasileira de Educação, v. 22, p. 1-15, 2017.

CUNHA, R. B. A importância do uso de autores dos estudos da linguagem nas referências bibliográficas dos trabalhos sobre alfabetização científica e letramento científico. Raído (online), v. 12, p. 11-20, 2018a.

CUNHA, R. B. O que significa alfabetização ou letramento para os pesquisadores da educação científica e qual o impacto desses conceitos no ensino de ciências. Ciência e Educação, v. 24, p. 27-41, 2018 b.

DEBOER, G. E. Scientific literacy: Another look at its historical and contemporary meanings and its relationship with science education reform. Journal of Research in Science Teaching, v. 37, p. 582-601, 2000.

CECCARELLI, L. Manufactured Scientific Controversy: Science, Rhetoric, and Public Debate. Rhetoric \& Public Affairs, v. 14, n. 2, p. 195-228, 2011.

DESJARDINS, A. et al. Harnessing Youth Activism with/in Undergraduate Education: A Case Study of Change Lab. In: MUELLER, M.; TIPPINS, D. (Org.). EcoJustice, Citizen Science and Youth Activism - Situated Tensions for Science Education. London: Springer, 2015. p. 349-361.

FENSHAM, P. J. Scepticism and trust: two counterpoint essentials in science education for complex socio-scientific issues. Cultural Studies of Science Education, v. 9, n. 3, p. 649661, 2014.

FREUDENTHAL, G. A rational controversy over compounding forces. In: MACHAMER, P.; PERA, M.; BALTAS, A. (Org.). Scientific controversies: philosophical and historical perspectives. 9. ed. Oxford: Oxford University Press, 2000. p. 125-142.

HAND, M. What should we teach as controversial? A defense of the epistemic criterion. Educational Theory, v. 58, n. 2, p. 213-228, 2008. 
HARDWIG, J. Epistemic dependence. The Journal of Philosophy, v. 82, p. 335-349, 1985.

HARDWIG, J. The role of trust in knowledge. The Journal of Philosophy, v. 88, p. 693-708, 1991.

HARMAN, G. Change in View. Cambridge, MA: MIT, 1986.

HODSON, D. Becoming Part of the Solution: Learning about Activism, Learning through Activism, Learning from Activism. In: BENCZE, L.; ALSOP, S. (Org.). Activist Science and Technology Education. London: Springer, 2014. p. 67-98.

HODSON, D. Realçando o papel da ética e da política na Educação Científica: algumas considerações teóricas e práticas sobre Questões Sociocientíficas. In: CONRADO, D. M.; NUNES-NETO, N. (Org.) Questões Sociocientíficas: fundamentos, propostas de Ensino e perspectivas para ações sociopolíticas. Salvador: EDUFBA, 2018. p. 27-57.

IPCC. Summary for Policymakers. In: STOCKER,T. F. D.; QIN, G. -K.; PLATTNER, M.; TIGNOR, S. K.; ALLEN, J.; BOSCHUNG, A.; NAUELS, Y.; XIA, V.; BEX P. M.; MIDGLEY (Eds.). Climate Change 2013: The Physical Science Basis. Contribution of Working Group I to the Fifth Assessment Report of the Intergovernmental Panel on Climate Change. Cambridge University Press, Cambridge, United Kingdom and New York, NY, USA, 2013.

JUNGES, A. L.; MASSONI, N. T. O consenso científico sobre aquecimento global antropogênico: considerações históricas e epistemológicas e reflexões para o ensino dessa temática. Revista Brasileira de Pesquisa em Educação em Ciências, v. 18, n. 2, p. 455-491, 2018.

KEMP, A. C. Science Educator's Views on the Goal of Scientific Literacy for All: An Interpretive Review of the Literature. In: Annual Meeting of the National Association for Research in Science Teaching, 2000, New Orleans. Atas [...]. 2000, p. 1-35.

KOLSTØ, S. D. Scientific literacy for citizenship: Tools for dealing with the science dimension of controversial socioscientific issues. Science Education, v. 85, n. 3, p. 291-310, 2001.

KUHN, T. S. The Structure of Scientific Revolutions. 2 ed. enlarged. Chicago and London: University of Chicago Press, 1970. 
LATOUR, B. Why has critique run out of steam? From matters of fact to matters of concern. Critical Inquiry, v. 30, n. 2, p. 225-248, 2004.

LEVINSON, R. A perspective on knowing about global warming and a critical comment about schools and curriculum in relation to socio-scientific issues. Cultural Studies of Science Education, v. 7, n. 3, p. 693-701, 2012.

LEVINSON, R. A theory of curricular approaches to the teaching of socio-scientific issues. Alexandria: Revista de Educação em Ciência e Tecnologia, v. 1, n. 1, p. 133-151, 2008.

MADHAV, N. et al. Pandemics: Risks, Impacts, and Mitigation. In: Disease Control Priorities: improving Health and Reducing Poverty. Washington DC: The International Bank for Reconstruction and Development / The World Bank, 2017.

MCMULLIN, E. Scientific controversies and its termination. In: EENGELHARD, A. L.; CAPLAN, A. L. Scientific controversies: case studies in the resolution and closure of disputes in science and technology. Cambridge: Cambridge University Press, 1987. p. 49-91.

NORRIS, S. P. Cynicism, Dogmatism, Relativism, and Scepticism: Can All These Be Avoided? School Science and Mathematics, v. 84, n. 6, p. 484-495, 1984.

NORRIS, S. P. Intellectual independence for nonscientists and other content-transcendent goals of science education. Science Education, v. 81, n. 2, p. 239-258, 1997.

NORRIS, S. P. Learning to live with scientific expertise: Toward a theory of intellectual communalism for guiding science teaching. Science Education, v. 79, n. 2, p. 201-217, 1995.

PEDRETTI, E.; NAZIR, J. Currents in STSE education: Mapping a complex field, 40 years on. Science Education, v. 95, n. 4, p. 601-626, 2011.

SADLER, T. D.; MURAKAMI, C. D. Socio-scientific Issues based Teaching and Learning: Hydrofracturing as an Illustrative context of a Framework for Implementation and Research. Revista Brasileira de Pesquisa em Educação em Ciências, v. 14, n. 2, p. 331-342, 2014.

SANTOS, W. L. P. dos. Debate on global warming as a socio-scientific issue: science teaching towards political literacy. Cultural Studies of Science Education, v. 9, n. 3, p. 663674, 2014. 
SANTOS, W. L. P. dos. Educação científica na perspectiva de letramento como prática social: funções, princípios e desafios. Revista Brasileira de Educação, v. 12, n. 36, p. 474-492, 2007.

SASSERON, L. H.; CARVALHO, A. M. P. DE. Alfabetização científica: uma revisão bibliográfica. Investigações em Ensino de Ciências, v. 16, n. 1, p. 59-77, 2011.

ZIMAN, J. O conhecimento confiável: uma exploração dos fundamentos para a crença na ciência. Campinas: Papirus, 1996.

ZIMAN, J. Real science: what it is and what it means. Cambridge: Cambridge University Press, 2000.

WEART, S. The discovery of global warming. Cambridge, Massachusetts: Harvard University Press, 2008. 